\title{
A dinâmica familiar no contexto da crise suicida
}

\author{
Liara Lopes Krüger - Tribunal de Justiça do Rio Grande do Sul, Porto Alegre, Brasil \\ Blanca Susana Guevara Werlang ${ }^{1}$ - Pontifícia Universidade Católica do Rio Grande do Sul, Porto Alegre, Brasil
}

\begin{abstract}
Resumo
Famílias inseridas no contexto suicida organizam suas relações em torno de histórias opressoras construídas através das gerações, que impedem o desenvolvimento de autonomia e continuidade. Este artigo objetiva pensar sistemicamente sobre a dinâmica familiar da crise gerada pela tentativa de suicídio de um dos seus membros. Neste estudo, seis famílias participaram de uma intervenção breve, desenvolvida com base na teoria sistêmica. Os dados foram analisados com base no Método de Comparação Constante, identificando-se categorias e a construção de hipóteses a respeito da dinâmica familiar no contexto da crise suicida. Os resultados mostram que os participantes estão limitados em sua capacidade de apoiar o desenvolvimento de uma identidade autônoma, porque a dinâmica familiar identifica as novas oportunidades de narrar a si mesmo como ameaça ao sistema de lealdades que mantém a continuidade da família, impedindo a renegociação desses códigos. O sofrimento se apresenta como emoção que limita novas trocas, surgindo o comportamento suicida como alternativa.

Palavras-chave: Suicídio, Dinâmica familiar, Teoria sistêmica.
\end{abstract}

\section{The family dynamics in the context of suicide crisis}

\begin{abstract}
Families inserted in the suicide context tend to organize their relations around oppressive histories constructed over generations that hinder the development of autonomy and continuity. This paper aims at thinking systematically about the family dynamics of the crisis generated by the suicide attempt of one of its members. In this study, six families participated of a brief intervention developed on the basis of the systemic theory. The Grounded Theory analysis procedures made possible the identification of the categories and the construction of hypotheses regarding the family dynamics within the context of the suicide crisis. The result shows that participants are limited in their capacity of supporting the development of an independent identity because the family dynamics identifies new opportunities of narrating to oneself as a menace to the system of loyalties that maintains the family continuity hindering the renegotiation of these codes. Suffering presents itself as emotion that limits new exchanges, giving rise to the suicide behavior as an alternative.

Keywords: Suicide, Family dynamics, Systemic theory.
\end{abstract}

O suicídio é um ato de violência autoinfligido que está, na maioria dos países, entre as dez principais causas de morte e entre as duas ou três mais frequentes em adolescentes e adultos jovens, constituindo-se num problema de saúde pública. O Brasil encontra-se no grupo de países com baixa taxa de suicídio, mas, como é um país populoso, atinge o nono lugar em números absolutos. Deixando-se à margem o problema da subnotificação, o suicídio respondeu por $0,8 \%$ de todos os óbitos da população brasileira em 2004 (Ministério da Saúde, 2006). Além do suicídio em si, há outro problema a ele ligado: o elevado número de pessoas que tentam o suicídio. Registros oficiais sobre tentativas de suicídio são escassos, estimando-se que o número supere o número de suicídios em pelo menos dez vezes.

\footnotetext{
1 Endereço para correspondência:

Programa de Pós-Graduação - Faculdade de Psicologia - PUCRS Avenida Ipiranga, 6681 - prédio 11 - sala 924 - 90619-900 - Porto Alegre - RS.

E-mail: bwerlang@pucrs.br
}

O suicídio deve ser abordado como uma dimensão que integra um possível contínuo de comportamentos que pode partir de pensamentos de autodestruição, passando por ameaças, tentativas de suicídio e finalmente a concretização do ato fatal (Cassorla, 2004). Estudar este fenômeno, que é resultado de uma complexa interação de vários fatores, implica considerar contribuições de vários campos do conhecimento (Werlang \& Botega, 2004). Destas diferentes visões proporcionadas por diversos estudos sobre o comportamento suicida, emergem elementos que estruturam histórias de sofrimento. Nesse contexto, a partir dos anos sessenta, estudiosos concluíram que o suicídio deveria ser compreendido, também, considerando-se o relacionamento familiar (Aldridge, 1999). Investigadores, como Kimmel e Weiner (1995) e Henry, Stephenson, Hanson e Hargett (1993), têm sugerido que os conflitos familiares estão relacionados com as tentativas de suicídio (fator de risco para o suicídio). Entretanto, cabe mencionar que a presença da instabilidade familiar, do rompimento de relacionamentos sociais e do 
insucesso nos esforços para resolução de problemas nas famílias nem sempre traz como consequência o comportamento suicida. Assim, sugere-se que a presença deste complexo fenômeno deve também considerar a possibilidade das características intrínsecas das famílias influenciarem na presença do ato suicida.

Nesse sentido, a pessoa, como membro de um grupo com o qual compartilha significados, quando atenta contra a sua vida, está inserindo a narrativa $\mathrm{da}$ experiência $\mathrm{da}$ crise suicida no repertório de histórias do sistema familiar. A crença de estar em crise emerge do sujeito a partir de diferentes falas sociais, constituídas na interação. Essa experiência de crise tende a alterar a intensidade dos vínculos emocionais na família e desta com o seu ambiente, limitando a capacidade em distinguir territórios, ideias, pessoas, experiências, umas das outras.

Famílias inseridas no contexto da crise suicida precisam de auxílio para que possam reconstruir-se como um sistema de apoio e proteção, justificando assim a relevância do presente estudo, que busca contribuir com a ampliação da compreensão em torno deste fenômeno para o planejamento de ações preventivas e de intervenções terapêuticas eficazes. $\mathrm{O}$ presente trabalho agrega o enfoque do pensamento sistêmico (Esteves de Vasconcelos, 2002) ao estudo do comportamento suicida. Apresenta a família como participante da pesquisa e o comportamento suicida como parte da história familiar na qual a pessoa que atenta contra sua vida é coautora das narrativas construídas, através do tempo, de geração em geração.

\section{Método}

Participaram do estudo seis famílias (da região metropolitana de Porto Alegre) inseridas no contexto da crise suicida em razão da presença da tentativa de suicídio de um dos seus membros. As famílias foram identificadas (após aprovação do projeto de pesquisa pelo Comitê de Ética da Pontifícia Universidade Católica do Rio Grande do Sul e pelas instituições hospitalares conveniadas para este estudo) por meio do integrante que tentou suicídio. Considerou-se o ingresso dessa pessoa em um pronto-socorro ou unidade de emergência de hospital geral, com internação de no mínimo $24 \mathrm{~h}$, ou ainda, numa unidade de internação psiquiátrica para onde tivesse sido encaminhada após o atendimento de emergência. Não participaram do estudo famílias com componentes que apresentavam transtorno psicótico, retardo mental e/ou que estivessem fazendo uso de medicação com propriedades que pudessem alterar a capacidade lógica e de raciocínio.

Esclarecidos os objetivos e procedimentos do estudo, todos os integrantes do grupo familiar assinaram o Termo de Consentimento Livre e Esclarecido. As famílias participaram, então, de uma intervenção, com enfoque sistêmico, projetada com base na experiência clínica e nos estudos desenvolvidos por teóricos da Terapia Breve (De Shazer, 1986, 1992; O'Hanlon \& Cade, 1995). A intervenção consistiu numa série de quatro sessões com duração média de 90 minutos, desenvolvidas no período de duas semanas, no próprio local da baixa hospitalar ou no Serviço de Atendimento e Pesquisa em Psicologia da Faculdade de Psicologia da PUCRS. A intervenção, realizada em quatro sessões, foi planejada para facilitar a expansão das idéias sobre a dinâmica familiar no contexto da crise suicida, a identificação de possibilidades para o enfrentamento dessa crise, assim como o encaminhamento de recursos terapêuticos. As sessões foram gravadas em fitas magnéticas de som e de imagem, proporcionando o registro das informações verbais e não-verbais e do contexto interacional.

A análise de dados foi realizada com base no Método de Comparação Constante - MCC (Grounded Theory, criado por Glaser e Strauss), no modelo proposto por Strauss e Corbin (1990) e com apoio nos estudos mais recentes de Valles (2003) e Borgatti (2006). Trata-se de um procedimento de análise que objetiva gerar, com base nas questões investigadas, categorias conceituais, suas propriedades e as relações entre elas, não havendo preocupação com a verificação, mas sim com a produção de novas ideias a respeito do fenômeno estudado (Valles, 2003). Dados sociodemográficos das seis famílias participantes do estudo são apresentados na Tabela 1 .

Com relação às características do comportamento suicida do membro das famílias que fez a tentativa, tem-se que quatro sujeitos usaram como método a ingestão de ansiolíticos, uma cortou os pulsos e uma ingeriu inseticida organoclorado. Três participantes fizeram tentativas de suicídio anteriores a esta última. Com exceção de Léa, que somente foi atendida em emergência ambulatorial, todas as demais permaneceram em unidade de internação psiquiátrica. 
Krüger, L. L., Werlang, B. S. G. A dinâmica familiar no contexto da crise suicida

Tabela 1 - Sumário das características sociodemográficas dos participantes que integram os seis grupos familiares

\begin{tabular}{|c|c|c|c|c|c|c|c|}
\hline Família & Participantes* & Parentesco & Idade & $\begin{array}{c}\text { Estado } \\
\text { civil }\end{array}$ & $\begin{array}{l}\text { Vínculo } \\
\text { conjugal }\end{array}$ & Ocupação & $\begin{array}{l}\text { Renda } \\
\text { familiar }\end{array}$ \\
\hline \multirow[t]{3}{*}{$\mathrm{A}$} & Léa** & Filha & 26 & Solteira & s/vínculo & s/emprego & 4 \\
\hline & Marília & Mãe & 48 & Separada & União & Enfermeira & s.mín \\
\hline & Ricardo & Filho & 22 & Solteiro & s/vínculo & s/emprego & \\
\hline \multirow[t]{2}{*}{ B } & Fabiana** & Filha & 21 & Solteira & s/vínculo & Industriaria & 12 \\
\hline & Eleonora & Mãe & 50 & Separada & s/vínculo & Industriaria & s. mín \\
\hline \multirow[t]{6}{*}{$\mathrm{C}$} & Sílvia** & Mãe & 45 & Casada & Casamento & Dona de & 13 \\
\hline & Carlos & Pai & 52 & Casado & Casamento & casa & s. mín \\
\hline & Milena & Filha & 26 & Solteiro & Namoro & Industriário & \\
\hline & Celina & Filha & 24 & Solteiro & Namoro & Estudante & \\
\hline & Rodrigo & Filho & 21 & Solteiro & Namoro & Professora & \\
\hline & & & & & & Estudante & \\
\hline \multirow[t]{2}{*}{$\mathrm{D}$} & Cláudia** & Filha & 22 & Solteira & s/vínculo & Estudante & 10 \\
\hline & Rosane & Mãe & 42 & Separada & União & Comerciante & s. mín \\
\hline \multirow[t]{4}{*}{$E$} & Mariana** & Filha & 21 & Solteira & s/vínculo & Estudante & 12 \\
\hline & Mara & Mãe & 48 & Casada & Casamento & Dona de & s. mín \\
\hline & Clóvis & Pai & 50 & Casado & Casamento & casa & \\
\hline & & & & & & Industriário & \\
\hline \multirow[t]{4}{*}{ F } & Gina** & Filha & 21 & Solteira & União & Comerciaria & 3 \\
\hline & Maria & Mãe & 51 & Solteira & União & Merendeira & s.mín \\
\hline & Dílson & Pai & 51 & Casado & Casamento & Taxista & 6 \\
\hline & Alda & $\begin{array}{c}\text { Avó- } \\
\text { paterna }\end{array}$ & 79 & Viúva & s/vínculo & $\begin{array}{c}\text { Dona de } \\
\text { casa }\end{array}$ & s. mín \\
\hline
\end{tabular}

* Nomes fictícios

** Integrante familiar com tentativa suicídio

\section{Resultados e discussões}

O material das sessões foi analisado e transformado em unidades de significados, buscando responder a questão: $O$ que isto significa? A comparação sistemática e aberta dos dados permitiu às pesquisadoras a geração e modificação das categorias, de acordo com o avanço do trabalho, e a revelação de novas possibilidades de análise. A identificação de eixos em torno dos quais trabalhar propiciou o desenvolvimento de categorias que traduziram relatos dos problemas das famílias - de como as pessoas percebem a si mesmas e de como se relacionam no contexto das histórias construídas através das gerações na família - e, ainda, as narrativas construídas em busca de soluções, revelando as seguintes categorias: (1) narrativas acerca de impedimentos para distinção da identidade de si mesmo; (2) narrativas sobre as crenças em torno do constituir vínculos; (3) narrativas sobre a dissipação de si mesmo e do sistema familiar; (4) narrativas familiares sobre como enfrentar a crise suicida. As operações analíticas realizadas conduziram à construção de algumas hipóteses a respeito da história dos participantes no que tange à dinâmica familiar no contexto da crise suicida.

Categoria 1. Narrativas acerca dos impedimentos para a distinção da identidade de si mesmo

As narrativas são vagas, empobrecidas, permeadas por histórias ambíguas e sentimentos de insegurança a respeito do tema: Quem sou eu? Os impedimentos para a distinção de si mesmo emergem pelos relatos de Mariana, Cláudia, Sílvia, Fabiana, Gina e Léa (pessoas que tentaram suicídio) e de suas famílias, cujos limites difusos entre $\mathrm{O}$ eu e o outro confundem ideias $e$ territórios.

Mariana vive na companhia de seus pais, Mara e Clóvis. Eles falam sobre o cotidiano, identificando como situações frequentes na família os "atritos entre mãe e filha". O que Mara nomeia de "coisinhas do dia a dia", Mariana classifica de intensa invasão da mãe no seu jeito de ser e de viver. O diálogo entre Mara e Mariana auxilia na compreensão desta dinâmica:

Mariana: "Ah, eu me sinto des... me sinto..."

Mara: "Desprotegida."

Mariana: "É."

Mara: "Insegura. Não sente vontade." 
Mariana: "Não mãe, eu sinto vontade, mas não me sinto bem assim, não sei explicar o que eu sinto realmente. Pára!"

Clóvis identifica o desejo ambíguo da filha de "querer liberdade" e, ao mesmo tempo, querer os pais perto, entre crescer e manter-se criança. Mara, porém, considera que Mariana precisa de sua presença constante, que "sempre foi assim", desde pequena, e que ela sabe o que Mariana precisa para sentir-se melhor:

Mara: "O que eu acho que impede ela ouvir a gente é... Porque se fizesse o que eu falo, ensino e digo pra ela fazer, ela seria diferente."

No contexto, onde o eu e o outro constituem um "nós" inseparável, a dificuldade de reconhecimento do outro traz, para o espaço conversacional da família, um vazio: a ausência de reciprocidade no diálogo. $O$ outro passa a ser prolongamento de si mesmo. O diálogo que se estabelece na família põe, constantemente, em dúvida os sentimentos e relatos do outro. Incompletude e incerteza, a respeito dos significados atribuídos às histórias, aparecem.

As famílias deste estudo percebem o empobrecimento das trocas estabelecidas entre eles e com outros contextos como mais um impedimento ao desenvolvimento da autonomia das pessoas na família. Clóvis e Mara contam que suas famílias de origem não se reúnem atualmente e que não possuem "muita proximidade com ninguém". Não teriam conseguido o entrosamento das duas famílias: "cada uma ficou na sua e a gente acaba no isolamento." Clóvis se preocupa também com a reclusão de Mariana:

O mundo dela é muito restrito. Até a gente tinha uma expectativa com a faculdade, que ela ia ter outro tipo de amizade, mais sólida, que pudesse de repente sair, formar um núcleo, um ciclozinho aí...

Cláudia, membro de outra família participante, vive hoje na companhia de sua mãe Rosane, do padrasto e irmão. Não conviveu com o pai, tendo morado até recentemente na companhia apenas da mãe. Esta relação de exclusividade traz para ambas fortes sentimentos, que "sufocam". Os limites difusos entre mãe e filha impedem que Cláudia possa se emancipar.
Isso me impressionava, eu me sentia sufocada, eu parecia um bebê de 2 meses, não podia fazer mais nada, estava ela (a mãe) na minha volta, sabe. Eu só acho, quando ela me liga uma vez ainda vai, o problema é que ela me liga umas três vezes.

Rosane, mãe de Cláudia:

A Clándia veio fazer o intensivo aqui. Foi a dor maior que eu tive na minha vida. Ela saiu, den tchau para ir e en fiquei aquela semana toda assim, em prantos...

A situação da família de Sílvia, que é casada com Carlos e tem três filhos adultos jovens, aponta a crise gerada por perdas financeiras, concomitantemente a uma maior emancipação dos filhos, como precipitadores da presença do comportamento suicida na família. Pais e filhos percebem-se atados por laços que foram inibindo iniciativas em torno da diferenciação do eu.

Filhos: Se não era em casa, ela participava de tudo da escola, era a mãe representante, ia nos passeios com a gente, de vez em quando a gente ficava irritado, sempre a mãe. Então era sempre envolvida com a gente, não largava.

Mãe: Porque no momento em que eles começaram a ser mais independentes a minha vida ficou um vazio. Eu era ocupada, vinte e quatro horas com eles.

Sílvia, participante que tentou suicídio, fala de sua relação com os filhos percebendo que pode ter desconsiderado o jeito de ser de cada um, o que aparece no discurso de sua filha Celina:

Filha: Mas exigia sim, tudo organizadinho, até hoje, o quarto tem que tá da forma que ela quer, não do jeito que en quero. Questionar a mãe? Questiono, mas não tem resposta. Não é discutivel.

Na família de Fabiana, que é a filha mais moça de três irmãos, os pais se separaram quando ela estava com 11 anos. Mãe e filha percebem-se como "um". Estas ideias surgem agregadas a relatos de constantes conflitos:

Fabiana: A gente briga. (Fala ao mesmo tempo da mãe.) Eu é que cuido dela. Por isso o desespero dela deu tá no hospital... E a minha mãe disse que não tava aguentando mais, que en tinha que viver por ela. Não sei o porquê, mas tudo... Para tudo... 
a mãe fala como é que tem que ser, então a gente far. Eu tenho medo dela se decepcionar comigo. Ab, eu acho que a mãe morria do coração Eu acho que dai sim eu vegetava.

A mãe de Fabiana conta uma história de isolamento que perpassa gerações. A avó materna vivia em casa "não saía para nada", Fabiana deixou a escola porque não saía de casa e Eleonora tem a sensação de que não vai ao pátio de sua casa há meses:

Ela (Fabiana) se tranca no quarto. Eu saía, ela tava dormindo, en chegava ela tava do mesmo jeito! E eu lembrava essa semana..., acho que far. meses que não vou no meu pátio! A Fabiana também. Sabe? Parece uma coisa meio doentia!

Gina, membro de outra família participante, é filha única e vive na companhia de sua avó paterna. Os pais se separaram quando ela tinha quatro anos. Gina tem vivido dividida entre a lealdade à família paterna e à materna. Aos vinte e um anos de idade, Gina sente-se com quinze e, às vezes, é percebida com menos.

Avó: "Ela é criada até hoje como um nenê."

Gina: Nunca deixam fazer nada, compram Danoninho. É tudo "inho". E assim vai, né, vó? O pai me trata como se eu tivesse 15, a mãe 10 e a vó 1 aninho... Mas a mãe (Maria) é pior, me protege demais, quando ela fica toda hora assim: "tira esse casaco. Come, te alimenta." Ela fala como se eu não soubesse essas coisas.

Maria: é, tá frio, tá calor."

Gina: "Bota um casaquinho. Mãe, eu sei que eu tenho que botar um casaco. É que ela fala por mim, aí eu não preciso falar."

Avó e mãe estão presas a uma imagem de Gina criança. O desejo de Gina de ser reconhecida como uma pessoa adulta e capaz esbarra no temor da perda desses vínculos:

Gina: "Ah, eu não quero que a mãe fique chateada." (Fala como uma criança, se encolhe.)

Maria: "Te ensinei a fazer arroz."

Gina: "Mas eu sabia."

Maria: "Ensinei a fazer um arroz. Aí tu aprendeu."

Gina (Com a cabeça baixa.): "Eu sei fazer arroz, sim."
Maria: "Alguma coisa eu tenho que te ensinar."

Gina: Eu disse que eu sabia. Daí ela pegou e... É que a mãe se mete demais, dai eu não consigo tomar a decisão que tem que tomar, porque ela tomou por mim.

Léa, uma das participantes que tentou suicídio, vive na companhia de sua mãe, Marília, do irmão Ricardo e de sua filha. Após a separação de Marília, não teve mais contato com o pai. Léa e Marília mantêm uma relação permeada por intensos conflitos, mas consideram a família com um forte vínculo entre eles: "cola, grude".

Léa: "O Ricardo (irmão de Léa) tá sempre grudado na mãe..."

Marília, mãe de Léa: $A$ Léa não fica sozinha, en me mudei, no outro dia, ela pegou os trapinhos e foi morar comigo (sorri balançando a cabeça em sinal de aprovação).

Léa: "Eu não gosto de ficar longe da mãe..."

Marília fala dos filhos como se fossem crianças que precisam ser cuidadas; da mesma forma, os filhos descrevem a mãe como se ela não fosse adulta suficiente para se proteger. Fazer pelo outro e ficar no lugar do outro são maneiras de proteger.

Marília: Ele (ex-marido) ficava mais agressivo comigo, mas dai ele descarregava na Léa, como ela me defendia, porque as crianças sempre ficaram do meu lado, né, dai se ele tivesse que bater, ele batia nela.

$\mathrm{Na}$ história da família surgem relatos sobre a ausência de reciprocidade nos diálogos. A violência impede o reconhecimento das pessoas como "um" em separado e engendra formas de "desaparecer" diante do outro, como conta a mãe de Léa sobre a sua família de origem:

Marília: Ele (avô materno de Léa) ficava mais agressivo, mais chato, mais pegajoso. Se contrariasse ele ficava mais agressivo. A mãe (avó de Léa) tinha medo dele (avô de Léa), por nós, então ela ficava sempre quietinha, não falava nada, então ela tapava nós, ela superprotegia nós. Sabe, ela tinha medo dele. Ela ficava quietinha e chorando sozinha, nós era pequenina, a gente nem sabia por que ela chorava, depois a gente foi vendo que ele machucava ela, né, sangrava. 
O material clínico destas famílias aponta para uma primeira hipótese sobre a dinâmica familiar no contexto da crise suicida, fundamentada nas narrativas acerca de impedimentos para a distinção da identidade de si mesmo. O conceito de impedimento, desenvolvido por Breulin, Schwartz e Kune-Karrer (2000), propõe que os sistemas constroem redes de significados que aprisionam os sujeitos para evitar a ocorrência de experiências ameaçadoras às crenças familiares. Propõe-se pensar estas famílias através das histórias de limites difusos entre o eu e os outros. As práticas de distinção entre o todo e as partes, nesses sistemas, surgem como ameaça à integridade do grupo familiar. A ausência de reciprocidade nos diálogos e o isolamento social emergem como coadjuvantes no empobrecimento das possibilidades para reconhecimento do outro. Movimentos em direção à autonomia são ressignificados, nesta trama, como deslealdade aos laços invisíveis que conformam o tecido da identidade familiar. Boszormenyi-Nagy e Spark (2001) explicam que os compromissos de lealdade constituem fibras imperceptíveis, porém resistentes, que mantêm unidos fragmentos complexos das relações na família, tendo como fundamento a preservação do grupo como tal. A incapacidade de cumprir obrigações gera sentimentos de culpa que se constituem em forças que mantêm esta lealdade. Neste contexto, a entrada no mundo adulto, as exigências de interação em diferentes ambientes redundam em uma sobrecarga e abrem portas para que a tentativa de suicídio apresente-se como alternativa.

\section{Categoria 2. Narrativas sobre as crenças em torno de constituir vinculos}

As crenças que emergem dos relatos colocam em destaque a lealdade às relações afetivas. Características derivadas das relações pais/filhos são transportadas através dos tempos para as demais. Neste contexto, a separação real ou imaginária gera intenso sofrimento e é percebida pelo outro como abandono. Iniciativas em torno de estabelecer novos vínculos geram ansiedade, pois demandam um novo equilíbrio entre os compromissos com a família e a inclusão dessa nova relação. Perturbadas com as novas exigências, as famílias entram em conflito, aumentando o sentimento de insuficiência e estreitando as possibilidades de realinhamento de suas lealdades.

Mara e Clóvis, pais de Mariana, consideram que suas dificuldades na relação com a filha iniciaram no período em que ela teve o primeiro namorado. Demonstram preferência por outras formas de relação que permitissem a continuidade de um vínculo mais estreito com a família e não um afastamento de Mariana:

Clóvis: Mas é como eu comentei antes, né, conhece uma pessoa só e parece que o mundo dela fica só girando em torno daquela pessoa, né, ela não...

Mara: Ela esquece até da gente nesse caso.

Mariana percebe a dificuldade de conciliar o namoro com os demais vínculos sociais, introduzindo a idéia de "exclusividade" como característica de seu relacionamento:

Mariana: Se bem que eu fiquei um tempo separada, mas isso é verdade, eu voltei com um monte de amigas minhas. Com essa minha amiga ai, a gente saiu um monte de vezes. Agora eu voltei com o meu namorado. Mas daí, eu vendo as coisas agora, bah, en tava me sentindo bem com a minha amiga lá... (Mariana dá uma risada meio constrangida).

Mara: "Mas por que não dá pra juntar o namorado e as amigas?"

Mariana: "Dá, só que ele não vai querer. Ele tá acostumado com exclusividade."

O processo de emancipação é lento, complicado e, às vezes, incompleto. Esta tensão gerada na família, ao ser mantida, ergue crenças em torno da incapacidade para separar sem romper. $\mathrm{Na}$ experiência deste conflito, as pessoas tendem a envolver um terceiro para difundir a ansiedade. A triangulação tende a estabilizar o conflito, mantendo os problemas. O relato de Mara, Clóvis e Mariana sobre o encaminhamento das questões de conflito entre mãe e filha auxiliam a compreender esta ideia:

Mariana: Não, primeiro eu fico irritada com a mãe e depois eu falo com o pai, olha pai, ela tá sendo assim, e o pai não faz nada. E aí, quando eu vejo que não vai sair nada, en tenho que me isolar mesmo.

Clóvis: "Não, eu me isolo quando a tua mãe fica atacada também."

Mara: "Cada um no seu canto e eu falando sozinha..." 
O tecido que reveste a relação de Cláudia e sua mãe Rosane, nesta outra família, construiu crenças que reconhecem, no afastamento físico ou emocional, uma perda irreparável. A experiência de Rosane com o pai de Cláudia engendrou uma história na qual a ruptura do vínculo gera sofrimento intenso e a impossibilidade de reparação desta dor que perpassa as demais relações. Mãe e filha experimentam o afastamento e o término do relacionamento com uma dor insuportável.

Rosane: É, eu não consegui ainda conciliar que a Clándia cresceu, é adulta, porque a primeira vez. que ela arrumou esse namoradinho, que ela foi pra praia, en fiquei o final de semana todo chorando. Ela tem uma vida agora, en não posso mais, né, quer dizer, trazer ela no colo.

Cláudia: "Eu me desesperei pelo meu namorado! Que eu o tinha perdido, que não tinha mais volta, esse tipo de coisa assim. Tanto desespero? Não senti."

Sílvia, outra participante, recorda que tudo mudou na sua família de origem quando os irmãos começaram a casar: nunca mais tiveram a mesma união, "sempre faltava alguém". Transporta esta experiência para a família atual e percebe que sua tristeza aumentou quando os filhos começaram a estabelecer novos vínculos:

Sílvia: Fins de semana mudaram, que eu sempre tinha um deles em companbia. Até que foi a Milena, até que foi a Celina, até que foi o Rodrigo com a namorada. Eu senti muito ciúmes quando o Rodrigo começou a namorar.

Sílvia cuidava da mãe e sentia-se presa entre o pai e a mãe, e hoje olha para a filha Celina identificando a mesma história: sua filha não sabe dizer não. Sempre disposta e prestativa, é a filha que rapidamente assumiu os cuidados da casa e da família. As iniciativas de Celina rumo à emancipação transitam em caminhos tortuosos, nos quais a "briga" é a tônica, seguida de um comportamento autodestrutivo de Sílvia:

Sílvia: Não, sei de repente, dessas vezes que eu (a filha) acabo sendo muito... grossa, assim de pegar firme. Chegar e dizer: Não, agora chega, não é assim! E é, geralmente, depois disso, que dá alguma crise, de tomar os remédios, ou até assim de passar o dia na cama, de piorar. Porque daí, ela fazendo isso a gente acaba voltando atrás.

$\mathrm{Na}$ família de Fabiana, as suas iniciativas de sair do isolamento constituindo relações de amizade acionam em sua mãe grande temor da filha sofrer, por um lado, e de deixá-la, por outro:

Fabiana: Tá no grude! Aí eu quero sair. As gurias começaram a me convidar. Ai, cada vez en rezo uma missa pra mãe me deixar sair. É que assim, ninguém presta pra ela. É que nenbuma amizade me serve.

Gina e Léa são duas participantes que viveram, cada uma em sua família, histórias permeadas por infidelidade e violência. Suas mães compartilham com as filhas ideias de que os "homens infernizam". As experiências de Gina e Léa nos seus relacionamentos afetivos ratificam essas histórias, apontando para a incapacidade de mudar e para o perigo de constituir novos vínculos:

Gina: Eu tenho namorados perturbados. Ai, quando eu sai duma relação, eu entrei numa outra furada, o cara era casado. Ai en dei um tempo: "Não, agora eu só vou dançar." Aí, foi numa dessas ai que en conbeci o Rafael, um louco.

Léa: Eu digo, né, Deus que me perdoe, parece um carma essa coisa de bebida, né, parece que a gente chega a procura alguém que beba pra se colá. O vô bebia, o pai bebia... Que nem a mãe diz, tem que arranjá um homem rico. Eu digo vou sair com uma placa no pescoço, porque eu só arranjo mașã podre. (Sorri.)

Léa conta ter ficado grávida num momento de sua vida em que sentia muita solidão, pois tinha rompido com o namorado com quem teve sua filha. Na separação, o bebê preencheu um vazio. Ao olhar para a história de sua infância, quando interrompia as brigas de seus pais para proteger a mãe de agressões, percebe sua filha na mesma situação:

Léa: Eu concordo que, quando eu brigo com a Gabriela, a mãe briga comigo do mesmo jeito que en briguei com ela, pra mim ficar magoada e pra mim vê como é bom a Gabriela ficar magoada. O que faz eu parar? Se a mãe se mete eu não paro, porque aí é culpa dela (a filha) que eu tô discutindo com a mãe. 
A partir destas histórias, uma segunda hipótese é construída (crenças para constituir vínculos) para responder à questão de como as famílias se movimentam desenvolvendo um contexto propício à inserção de ideias de morte e morrer. Para essas famílias parece que estabelecer vínculos em outros contextos que não o familiar traz sentimentos contraditórios de insuficiência: o desejo de emancipação, por um lado, e o medo da violação dos códigos familiares, por outro. As expectativas compartilhadas, não escritas, mas contadas através das histórias familiares, justificam este temor. Os pais desejam que suas filhas estabeleçam novos relacionamentos, criticando o isolamento, mas sentem-se temerosos com relação à capacidade delas de dar conta destas novas lealdades sem abandoná-los. Ainda, as filhas fazem incursões descuidadas em direção ao novo, confirmando suas inabilidades para conciliar todas essas exigências. A intensidade e proximidade com os namorados e companheiros geram rapidamente intensa dependência, e imaginar, ou passar pela separação, traz uma dor insuportável. O apego e isolamento destas famílias na relação com outros contextos foi o substrato no qual elas se fundaram como sistemas identificáveis em meio aos demais. Ao deparar-se com as possibilidades originais de "ser" que permeiam as relações contemporâneas, mediante novas alternativas de relacionamento proporcionadas pelas tentativas de diferenciação dos seus membros, sentem-se sobrecarregadas, cansadas, invadidas. O terceiro surge na relação como uma possibilidade de dissipação da ansiedade gerada pela crise emancipatória. A separação decorrente do término de um namoro ou a saída dos filhos da casa materna é experienciada nesse ambiente como a perda de uma parte de si mesmo que impossibilita a continuidade da vida.

\section{Categoria 3. Narrativas sobre a dissipação de si mesmodo sistema familiar}

Histórias em torno dos sentimentos de insuficiência, de incapacidade para dar conta das ocorrências do cotidiano, especialmente no que diz respeito aos impedimentos diante de inúmeras possibilidades de ser e de viver a vida, são descritas por meio de relatos de solidão, dor, sofrimento. Os descontroles - desatinos, loucuras - parecem exaurir os recursos pessoais e da família para lidar com a crise. O desejo de descansar, dormir, sumir confunde-se com o desejo de morrer. Retidos na crise, atos, que causam danos físicos e emocionais à própria vida, aparecem como uma opção.

Mara e Clóvis viajaram no final de semana sem Mariana. Nesse período, Mariana brigou com o namorado. Sozinha, um intenso sentimento de abandono a invadiu. A dor insuportável faz com que não consiga responder pelos seus atos: "desatina"

Mariana: Eu ficava sożinha, eles (os pais) não tão nem aí. Iam pra praia. Eu tava com o meu namorado e eu não tava falando com ninguém. Daí, nesse dia, en tinha brigado com o men namorado... Como é que en vou dizer, quando en me sinto sozinha, eu fico bem desatinada. Ai en não respondo pelos meus... Dai fiquei pensando: pô, agora não vai ter mais ninguém, então quero dormir $e$ ai tomei.

Cláudia fala do seu desejo de morrer após o término do namoro. Acredita que, sem ele, não é capaz de dar "conta de tudo a sua volta":

Cláudia: Isso foi em setembro, ele terminou e eu fiquei... sem chão assim, en sabia que ele não voltaria, en sei até hoje... E o que en queria fazer era me matar mesmo. Eu não conseguia mais trabalhar. Um horror! Eu não tinha mais vontade. Ab, um alivio pro que eu tava sentindo. Eu não queria mais sofrer, en decidi que en queria morrer. Ai, eu não sei assim... porque tem outras opções. E o morrer não, o morrer en não sofreria mais. Aliviar a minha dor, com certeza. Apesar de que se eu conseguisse, faria muitas outras pessoas sofrerem também, né? A minha mãe sofreria a dor que eu tava sofrendo.

Sílvia percebe a entrada dos filhos no mundo adulto como a perda de uma parte de si mesma e o fím da família. Não sabe como preencher este vazio. Conta esta história como se estivesse narrando a história vivida com a sua própria mãe: vem a dor e o desejo de não prender os seus filhos da forma como se sentiu atada à doença da mãe:

Sílvia: Vazio que en tenho dificuldade de preencher. Tenho dificuldade de ocupar esse tempo que eu tenho hoje pra mim, sem ter que viver tanto a vidinha deles (os filhos). Não consigo me enxergar. Parece que eu não existo. Eu Silvia. Fui murchando e eles foram crescendo. Sabe, eu sempre tive uma certa identidade com a minha mãe nesse sentido, quando eu comecei a sentir que eu tava 
deprimida, eu não quero que meus filhos tenham... tudo que en vivi...

O sentimento de incapacidade, de não dar conta de si mesma e especialmente de não conseguir liberar-se das expectativas maternas alimentam o desejo de morte em outra participante.

Fabiana: (Baixa a cabeça.)... Tu é uma incapaz, tu não serve pra nada, tu só dá desgosto. E assim tu começa a pensa. Ai aquela coisa volta a dizer: "tu tem que morrer, tu é uma desgraçada, tu é uma insignificante." Ai é assim... O que fiz. da minha vida?... Porque dai en comecei a me lembrar que cada vez que eu tinha que sair, a mãe não confiava em mim, ai que eu fui... fiz.. (tentativa de suicídio).

Eleonora, mãe de Fabiana, ao contar histórias de sua família, parece legitimar a morte como uma possibilidade de lidar com as questões de lealdade familiar:

Eleonora: Eu disse pra ela, eu também cortei o meu pulso... Por causa da mãe! Porque a mãe não deixava en sair, en namorar,... en não gostava de mim também!

A mãe de Maria tentou suicídio. Ela a socorreu e nunca mais falaram sobre isso. Hoje, diante da experiência de morte vivida com sua filha, busca entender o que se passa. Gina conta para a mãe seu sentimento de vazio, desejo de desaparecer.

Maria: É porque a gente não entende o porquê. Eu digo, deve ter algum problema lá, sabe... Uma fraqueza, lá sei en o que passa na cabeça de uma pessoa que tenta.

Gina: (Com a cabeça baixa.) Eu não penso em outra coisa, só penso em querer... ir embora pra sempre. Não passa nada. Se tu pensar, tu não faz. É, só passa coisa ruim, um vazio.

Léa fala de duas partes que brigam entre si dentro dela: o medo do abandono, por um lado, e, por outro, o desespero por não conseguir se liberar do ciclo de violência que $a$ ata ao namorado. A solidão, o cansaço e o desejo de sumir aparecem como possibilidades para mudar esta história:

Léa: Eu sempre me... Eu tenho essas minhas loucuras. Assim de me sentir sozinha de... [...]
Esse sofrimento, essa angústia que eu fico de quando ele some, sabe (chorando). Ai, é que parece que, pra ver se ele pára, não sei, ai (suspira) sabe um desespero que parece que a pessoa não vai parar nunca de infernizar? Sei lá, ai, às vezes eu penso em morrer, quando ele tá incomodando muito, às vezes, en penso: ai que vontade de sumir. [...] Parece que eu tô dormenta!

Como terceira hipótese sobre a dinâmica familiar no contexto da crise suicida surgem as narrativas sobre a dissipação de si mesmo e do sistema familiar. Os recursos mostram-se esgotados, e, invadidas pelos outros, ao tentar a libertação rumo à individualidade, as pessoas são frustradas. A ampliação do sistema, com a entrada de novos membros, ao invés de um meio criativo para reinventar a si mesmo e a família, aparece como mais um impedimento. As histórias opressoras que dominam o cenário familiar através das gerações estão em consonância com as narrativas dos sujeitos sobre si mesmos, estreitando os caminhos rumo à autorreflexão. Um vazio do "eu" diante do temor do abandono do outro traz ideias de morte, de não existir, de insuficiência para resgatar a si mesmo.

Categoria 4. Narrativas familiares sobre enfrentar a crise suicida

As histórias familiares, em torno de como lidar com a crise gerada pela presença da experiência da tentativa de suicídio na família, aparecem timidamente inseridas num texto de esperança que, apesar do relato restrito em comparação ao corpo do repertório, vieram a constituir-se numa categoria, destacando-se como diferente das demais. A ideia da inserção de atividades, trabalho, estudo surge entre os participantes como uma parte importante de suas vidas, por intermédio da qual podem experimentar outras formas de ser, agregando novidade. Algumas famílias reportam-se ao realinhamento nas relações familiares como possibilidade para o renarrar das histórias restritivas, agregando um outro olhar sobre a crise.

Sílvia: E poder tá aqui nos trouxe, assim, uma nova visão de vida, a esperança de dias melhores e que cada um vai poder cuidar da sua vida e cuidar de si mesmo e, ao mesmo tempo, estarmos todos juntos, né? E que a gente pode ir atrás, ir em busca. Eu acho que é um novo, eu vejo uma luz. no fim do túnel. 
Marília: Eu pensei que, né, a gente precisava melhorar, fazê um tratamento, aceitá ajuda, assim, né, das pessoas, se abri..., um pouco. Ai, dai a gente conseguia vivê, porque ela (Léa) é assim, é alegre, quando ela tá bem... ai a gente consegue sentar e conversá, sabe, ela trata bem a filha....

Rosane: Eu não posso embrulhar o namorado $e$ trazer pra ela e nem tenho ideia mais de fazer isso, né, eu quero que agora a vida seja dela, eu quero ajudar, mas não da forma que eu fazia antes. Eu aprendi um pouco disso daí. E eu acho que eu vou ter que começar a pensar que ela já cresceu e eu já ajudei até demais.

Essas famílias configuraram suas histórias a partir da crise suicida. Ao selecionar partes da experiência que tenham sentido nesta narração, as pessoas vão incrementando os relatos que mantêm o significado problemático. Nesse processo, tendem a confundir a sua própria história com a história de seus problemas, de forma que, com o passar do tempo, não conseguem mais discriminar uma da outra. A hipótese que emerge das narrativas familiares sobre enfrentar a crise suicida refere-se à capacidade dos participantes distinguirem o problema como uma parte de suas vidas, restando outras partes a serem acessadas com potencial para movimentar-se de forma criativa em busca de perspectivas inovadoras que conciliem a autonomia e a continuidade.

A análise dos significados compartilhados pelas famílias participantes deste estudo oferece elementos para uma discussão a respeito de assuntos relevantes na compreensão dos sistemas familiares. A composição dos relatos produzidos no transcorrer deste processo revela histórias familiares permeadas por indiscriminações em torno da pergunta: Quem sou eu? Os limites entre o "eu" e o outro parecem ter perdido a sua plasticidade, constituindo-se num impedimento para movimentos rumo à diferenciação. Apego e isolamento aparecem como o substrato para a formação dessas famílias como sistemas identificáveis. Neste contexto, a qualidade primeira do diálogo, reciprocidade, é escassa e inibe oportunidades de gerar significados originais. Se as histórias dos outros não são ouvidas e afirmadas, a conversação torna-se cada vez menos coordenada e tem-se uma situação impeditiva para a outra contribuição do diálogo, a autorreflexividade.

A autorreflexão (Gergen, 1999) torna-se possível porque, ao participar de diversas relações - na família, na comunidade, no trabalho, no lazer -, carrega-se junto um repertório de significados, podendo-se falar com muitas vozes. No caso dessas vozes poderem ser identificadas e utilizadas quando se fala sobre as diferenças, torna-se possível uma transformação. Nas famílias em estudo, as oportunidades de trocas em contextos diversos são percebidas como uma ameaça à integridade do sistema, tornando as alternativas para inserir novidade nos relatos uma violação dos códigos de lealdade familiar. As novas relações, estabelecidas também em torno de crenças que põem em destaque o apego excessivo, a "exclusividade", demandam lealdades inéditas, que, agregadas às exigências familiares, trazem uma sobrecarga adicional para todas as relações. $\mathrm{O}$ isolamento surge então como um refúgio, uma possibilidade de cessar as intensidades dessas trocas, por um lado, alimentando, por outro lado, sentimentos de insuficiência. A solidão, a percepção de não dar conta de "tuuuudo a minha volta" (participante Cláudia) produz um vazio de possibilidades de ser, aqui significado como uma dissipação de si mesmo.

A confiança mútua, que é uma forma de desenvolver gradativamente uma identidade autônoma sem perder a continuidade, constrói-se na possibilidade de assumir, na família, compromissos de lealdade baseados em códigos de reciprocidades que propiciem a cada um recriar as suas próprias histórias. Os objetivos pessoais de autonomia aparecem, assim, inextrincavelmente vinculados à capacidade de um relacionamento com responsabilidade mútua (Fishbane, 1998). A aquisição de uma noção de si mesmo, único, singular e contínuo, faz-se possível quando o sujeito vai construindo também limites entre o "eu" e os outros, distinguindo a si mesmo e ao sistema a que pertence.

Os sistemas emocionais apoiadores da autonomia permitem a manutenção de crenças no valor da família e na importância de vincular-se aos outros. O estabelecimento de trocas entre diferentes sistemas, propiciadas neste contexto, enriquece o repertório de alternativas para enfrentamento das crises, flexibilizando padrões de relacionamento e auxiliando o desenvolvimento de capacidades para a mudança. O sentimento de competência é reforçado na família, ratificando crenças sobre a necessidade de intimidade e o desejo de pertencer, que trazem consigo satisfação e segurança para os membros do sistema familiar, tornando, assim, possível a invenção de novas formas de ser si mesmo e de ser família.

As famílias participantes deste estudo, no entanto, percebem-se limitadas para apoiar e 
proteger os seus membros, porque suas experiências familiares passadas e presentes geraram a crença no perigo de vincular-se aos outros, buscando formas de proteção. O empobrecimento das pautas interativas reduz as trocas e as possibilidades de narrar as suas próprias histórias e de escutar outras e, desta forma, criar novas maneiras de lidar com as experiências cotidianas. As incursões em busca de novos contextos de relação trazem inúmeras exigências agregadas ao temor de ruptura. O sofrimento, nesse ambiente, apresenta-se com emoções que limitam a entrada do sujeito em algumas conversações, surge a solidão, os recursos parecem insuficientes, a exaustão torna o comportamento suicida um caminho possível.

\section{Considerações finais}

A presença do comportamento suicida na família pode ser percebida, num primeiro momento, como uma questão pontual decorrente da situação identificada como desencadeadora do ato autodestrutivo: o emprego perdido, o rompimento com o namorado, a adultez dos filhos, a falta de ocupação. Porém, a "onda de choque emocional" (Bowen, 1991), que reverbera por toda a rede de afinidades a partir desta experiência, insere questionamentos em torno de como viver a vida. A possibilidade da perda iminente implica o restabelecimento de expectativas, realização de novas escolhas, aceitação de rompimentos na família. A crise desencadeada pela tentativa de suicídio é uma experiência complexa, construída pelas histórias passadas, pelas presentes e pelas expectativas em torno do futuro, cujo sofrimento pode paralisar a família, gerando crenças de que o desejo de morte constitua uma ameaça à dissipação do sistema familiar. A mesma crise pode também vir a ser um catalisador de criatividade, à medida que as famílias consigam compartilhar a experiência, inserindo novidade em suas histórias.

A trajetória que se estabelece entre os pensamentos, ameaças, tentativas e a concretização da morte autoinfligida oferece um tempo propício à intervenção preventiva da morte por suicídio. Nesse espaço, foi introduzida a proposta deste estudo. As famílias participantes, ao aceitarem colaborar, ratificam a ideia de que é no momento de crise que a oportunidade de mudança se apresenta. A produção de um espaço, no qual a escuta propicie um ambiente em que as vozes dessas famílias possam entoar um canto original que, muito lentamente, aproxime o estranho do familiar, parece constituir uma possibilidade de acessar a parte das histórias dessas famílias que espera reconhecer a si mesma como protagonista de histórias libertadoras. Apresentou-se, assim, a intervenção sistêmica breve com famílias como estratégia de prevenção do suicídio.

\section{Referências}

Aldridge, D. (1999). Suicide: the tragedy of holplessness. London: Jessica Kingsley Publishers.

Borgatti, S. (2006). Introduction to Grounded Theory. Obtido do Eorld Wide Web: http://www.analytictech.com/mb870/introdo GT.htm

Boszormenyi-Nagy, I. \& Spark, G. M. (2001). Lealtades invisibles. Buenos Aires: Amorrortu.

Bowen, M. (1991). De la família al individuo: la diferenciación del si mesmo en el sistema familiar. Barcelona: Paidós.

Breulin, D., Schwartz, R. \& Kune-Karrer, B. (2000). Metaconceitos: transcendendo os modelos de terapia familiar. Porto Alegre: Artmed.

Cassorla, R. (2004). Suicídio e autodestruição humana. Em N. Botega \& B. S. G. Werlang (Orgs.). Comportamento Suicida (pp. 21-33). Porto Alegre: Artmed.

De Shazer, S. (1986). Terapia familiar breve. São Paulo: Summus.

De Shazer, S. (1992). Claves en psicoterpia breve: Una teoria de la solución. Barcelona: Gedisa.

Esteves de Vasconcelos, M. J. (2002). Pensamento sistêmico: novo paradigma da ciência. Campinas: Papirus.

Fishbane, M. (1998). I, thou and we: a dialogical approach to couples therapy. Journal of Marital and Family Therapy, 24(1), 41-58.

Gergen, K. (1999). Rumo a um vocabulário do diálogo transformador. Em D. F. Schnitman \& S. Littlejhon (Orgs.). Novos paradigmas em mediação, (pp. 29-45). Porto Alegre: Artmed.

Henry, C., Stephenson, A., Hanson, M. \& Hargett, W. (1993). Adolescent suicide and families: an ecological approach. Adolescence, 28(110), 291 308.

Kimmel, D. C. \& Weiner, I. B. (1995). Adolescence: 
a developmental transition. New York: J. Willey.

Ministério da Saúde (2006). Prevenção do suicídio: manual dirigido a profissionais das equipes de saúde mental. Brasília: Ministério da Saúde, OPAS, UNICAMP.

O’Hanlon, W. H. \& Cade, B. (1995). Guía breve de terapia breve. Barcelona: Paidós.

Strauss, A. \& Corbin, J. (1990). Basics of Qualitative Research. Grounded Theory producers and techniques. London: Sage.
Valles, M. S. (2003). Técnicas cualitativas de investigación social: reflexión metodológica y práctica profesional. Madrid: Sínteses.

Werlang, B. G. \& Botega, N. J. (2004). Introdução. Em N. Botega \& B. S. G. Werlang (Orgs.). Comportamento suicida (pp. 17-18). Porto Alegre: Artmed.

Sobre as autoras:

Liara Lopes Krüger é bacharel em Serviço Social e doutora em Psicologia pela Pontifícia Universidade Católica do Rio Grande do Sul - PUCRS. Perita e mediadora familiar no Tribunal de Justiça do Rio Grande do Sul - TJRS, é terapeuta de família e casal.

Blanca Susana Guevara Werlang é psicóloga clínica e doutora em Ciências Médicas/Saúde Mental pela Universidade Estadual de Campinas - UNICAMP. Professora titular dos cursos de graduação e pósGraduação em Psicologia da Faculdade de Psicologia da Pontifícia Universidade Católica do Rio Grande do Sul - PUCRS, é membro do Grupo de Trabalho para implantar a Estratégica Nacional de Prevenção ao Suicídio (Ministério da Saúde/Brasil). 